\title{
Lateralization and cognitive systems
}

\author{
Sebastian Ocklenburg ${ }^{1}$, Marco Hirnstein ${ }^{2}$, Christian Beste $^{3}$ and Onur Güntürkün ${ }^{1}$ \\ Biopsychology, Institute of Cognitive Neuroscience, Ruhr-University Bochum, Bochum, Germany \\ ${ }^{2}$ Bergen fMRI Group, Department of Biological and Medical Psychology, University of Bergen, Bergen, Norway \\ ${ }^{3}$ Cognitive Neurophysiology, Department of Child and Adolescent Psychiatry, Faculty of Medicine of the Technische Universität Dresden, Dresden, Germany \\ ${ }^{*}$ Correspondence: sebastian.ocklenburg@rub.de
}

Edited and reviewed by:

Bernhard Hommel, Leiden University, Netherlands

Keywords: handedness, executive function, laterality, lateralization, hemispheric asymmetry, brain, language, brain structure

Lateralization of brain and behavior in both humans and nonhuman animals is a topic that has fascinated neuroscientists since its initial discovery in the mid of the nineteenth century (Broca, 1861; Dax, 1865; Oppenheimer, 1977; Ströckens et al., 2013). Hemispheric asymmetries are abundant in the anatomy, neurochemistry and cytoarchitecture of the vertebrate brain and over the decades, a number of cognitive abilities have been shown to heavily rely on lateralized processing in the brain, the most widely investigated being language (Corballis, 2012; Ocklenburg et al., 2013b). Other cognitive domains that depend on lateralized processing include emotional processing (Önal-Hartmann et al., 2012), face and body perception (Thoma et al., 2014), spatial attention (Duecker et al., 2013), fine motor skills (Arning et al., 2013) and memory (Habib et al., 2003)_just to name a few. However, the impact of lateralization of brain function is not limited to these "classical" domains of lateralization research. The efficiency of higher cognitive processes in the vertebrate brain does not only depend on the involved cognitive systems themselves, but also on earlier information processing stages (Knudsen, 2007). Therefore, functional hemispheric asymmetries in stimulus processing can affect the efficiency of virtually any cognitive domain. This principle has recently been demonstrated for executive functions mediated by fronto-striatal networks, including working memory processes (Beste et al., 2010a,b, 2011, 2012). Ocklenburg et al. (2011, 2012) could show that the efficiency of executive functions like response inhibition or task switching is modulated when functional hemispheric asymmetries affect stimulus processing.

Based on these observations, the present Frontiers in Cognition Research Topic aimed to further investigate the relationship of lateralization and cognitive systems in the vertebrate brain. Overall, the Research Topic encompasses more than 30 novel publications, ranging from Original Research Articles to Reviews and Mini Reviews, Perspective Articles and Hypothesis and Theory Articles. From the beginning, the present Research Topic was conceptualized with a comparative multi-disciplinary inter-species approach in mind. This idea is reflected in the broad diversity of animal models included in the Research Topic, ranging from invertebrates (Frasnelli, 2013) to different species of birds (Manns and Ströckens, 2014; Rugani et al., 2014) and primates (Hopkins et al., 2014). In addition to animal research, several studies examined how lateralization impacts the functioning of different cognitive systems in the human brain. For example, it was investigated how handedness is related to other brain functions such as language lateralization (Carey and Johnstone, 2014), approach/avoidance motivation (Hardie and Wright, 2014), perceptual asymmetries (Marzoli et al., 2014), semantic priming (Fagard et al., 2014), response speed in the orthogonal Simon task (Iani et al., 2014) and cognitive performance in general (Prichard et al., 2013; Scharoun and Bryden, 2014). These studies are complemented by a review article investigating how twin studies could be useful in the quest to understand the complex interrelations of lateralization and cognitive systems (Ooki, 2014) as well as by a large-scale anatomical work investigating the effect of handedness on the structure of the cerebral cortex (Guadalupe et al., 2014). The relation of structural and functional asymmetries was also the topic of review article that investigated the cortical microstructural basis of lateralized cognition (Chance, 2014). Moreover, several authors investigated auditory lateralization (e.g., Specht et al., 2014). For example, Hirnstein et al. (2014a; Erratum in Hirnstein et al., 2014b) investigated how language lateralization measured with the Dichotic Listening Task relates to cognitive performance. The same task was used in a new smartphone version by Bless et al. (2013) who investigated the feasibility of conducting research on the interaction between lateralization and cognitive systems using a smartphone application. With more than 5500 article views and an AM score of more than 50 by the time this editorial was written, this article has gained more online attention than almost any other work published in Frontiers in Cognition. Other authors investigated visual lateralization (Asanowicz et al., 2013; Pellicano et al., 2013; Helon and Króliczak, 2014), asymmetries in emotional processing (Propper and Brunyé, 2013; Grimshaw and Carmel, 2014), behavioral lateralization (Morton, 2013; Corbetta et al., 2014), and asymmetries in face (Coronel and Federmeier, 2014) and body representation (Hach and Schütz-Bosbach, 2014), as well as in word generation (Meyer et al., 2014) and word recognition (Izura et al., 2014). Finally, some authors also investigated the impact of lateralized processing on executive functioning, the topic which had initially inspired this Research Topic (Marsh et al., 2013; Ocklenburg et al., 2013a; Kéita et al., 2014; Stock and Beste, 2014).

Taken together, the wide variety of cognitive systems in different species covered in the present Research Topic highlights the enormous importance of understanding how and why the vertebrate brain is asymmetrically organized for almost any subfield within cognitive neuroscience. We hope that the excellent papers 
assembled in the present Research Topic will help to stimulate more research aimed at understanding the complex mechanisms underlying the interaction between hemispheric asymmetries in stimulus perception and higher cognitive systems.

\section{REFERENCES}

Arning, L., Ocklenburg, S., Schulz, S., Ness, V., Gerding, W. M., Hengstler, J. G., et al. (2013). PCSK6 VNTR polymorphism is associated with degree of handedness but not direction of handedness. PLOS ONE 8:e67251. doi: 10.1371/journal.pone.0067251

Asanowicz, D., Smigasiewicz, K., and Verleger, R. (2013). Differences between visual hemifields in identifying rapidly presented target stimuli: letters and digits, faces, and shapes. Front. Psychol. 4:452. doi: 10.3389/fpsyg.2013.00452

Beste, C., Heil, M., Domschke, K., and Konrad, C. (2010a). The relevance of the functional 5-HT1A receptor polymorphism for attention and working memory processes during mental rotation of characters. Neuropsychologia 48 , 1248-1254. doi: 10.1016/j.neuropsychologia.2009.12.025

Beste, C., Heil, M., and Konrad, C. (2010b). Individual differences in ERPs during mental rotation of characters: lateralization, and performance level. Brain Cogn. 72, 238-243. doi: 10.1016/j.bandc.2009.09.005

Beste, C., Ness, V., Falkenstein, M., and Saft, C. (2011). On the role of frontostriatal neural synchronization processes for response inhibition-evidence from ERP phase-synchronization analyses in pre-manifest Huntington's disease gene mutation carriers. Neuropsychologia 49, 3484-3493. doi: 10.1016/j.neuropsychologia.2011.08.024

Beste, C., Ness, V., Lukas, C., Hoffmann, R., Stüwe, S., Falkenstein, M., et al. (2012). Mechanisms mediating parallel action monitoring in fronto-striatal circuits. Neuroimage 62, 137-146. doi: 10.1016/j.neuroimage.2012.05.019

Bless, J. J., Westerhausen, R., Arciuli, J., Kompus, K., Gudmundsen, M., and Hugdahl, K. (2013). "Right on all occasions?"-on the feasibility of laterality research using a smartphone dichotic listening application. Front. Psychol. 4:42. doi: 10.3389/fpsyg.2013.00042

Broca, P. P. (1861). Perte de la parole, ramollissement chronique et destruction partielle du lobe antérieur gauche du cerveau. Bull. Soc. Anthropol. 2, 235-238.

Carey, D. P., and Johnstone, L. T. (2014). Quantifying cerebral asymmetries for language in dextrals and adextrals with random-effects meta analysis. Front. Psychol. 5:1128. doi: 10.3389/fpsyg.2014.01128

Chance, S. A. (2014). The cortical microstructural basis of lateralized cognition: a review. Front. Psychol. 5:820. doi: 10.3389/fpsyg.2014.00820

Corballis, M. C. (2012). Lateralization of the human brain. Prog. Brain. Res. 195, 103-121. doi: 10.1016/B978-0-444-53860-4.00006-4

Corbetta, D., Friedman, D. R., and Bell, M. A. (2014). Brain reorganization as a function of walking experience in 12-month-old infants: implications for the development of manual laterality. Front. Psychol. 5:245. doi: 10.3389/fpsyg.2014.00245

Coronel, J. C., and Federmeier, K. D. (2014). Task demands modulate decision and eye movement responses in the chimeric face test: examining the right hemisphere processing account. Front. Psychol. 5:229. doi: 10.3389/fpsyg.2014.00229

Dax, M. (1865). Lésions de la moitié gauche de l'encéphale coincidant avec l'oubli des signes de la pensée. Bull. Hebd. Méd. Chir. 33, 259-262.

Duecker, F., Formisano, E., and Sack, A. T. (2013). Hemispheric differences in the voluntary control of spatial attention: direct evidence for a righthemispheric dominance within frontal cortex. J. Cogn. Neurosci. 25, 1332-1342. doi: 10.1162/jocn_a_00402

Fagard, J., Sirri, L., and Rämä, P. (2014). Effect of handedness on the occurrence of semantic N400 priming effect in 18-and 24-month-old children. Front. Psychol. 5:355. doi: 10.3389/fpsyg.2014.00355

Frasnelli, E. (2013). Brain and behavioral lateralization in invertebrates. Front. Psychol. 4:939. doi: 10.3389/fpsyg.2013.00939

Grimshaw, G. M., and Carmel, D. (2014). An asymmetric inhibition model of hemispheric differences in emotional processing. Front. Psychol. 5:489. doi: 10.3389/fpsyg.2014.00489

Guadalupe, T., Willems, R. M., Zwiers, M. P., Arias Vasquez, A., Hoogman, M., Hagoort, P., et al. (2014). Differences in cerebral cortical anatomy of left- and right-handers. Front. Psychol. 5:261. doi: 10.3389/fpsyg.2014.00261

Habib, R., Nyberg, L., and Tulving, E. (2003). Hemispheric asymmetries of memory: the HERA model revisited. Trends Cogn. Sci. 7, 241-245. doi: $10.1016 /$ S1364-6613(03)00110-4
Hach, S., and Schütz-Bosbach, S. (2014). In (or outside of) your neck of the woods: laterality in spatial body representation. Front. Psychol. 5:123. doi: 10.3389/fpsyg.2014.00123

Hardie, S. M., and Wright, L. (2014). Differences between left- and right-handers in approach/avoidance motivation: influence of consistency of handedness measures. Front. Psychol. 5:134. doi: 10.3389/fpsyg.2014.00134

Helon, H., and Króliczak, G. (2014). The effects of visual half-field priming on the categorization of familiar intransitive gestures, tool use pantomimes, and meaningless hand movements. Front. Psychol. 5:454. doi: 10.3389/fpsyg.2014.00454

Hirnstein, M., Hugdahl, K., and Hausmann, M. (2014a). How brain asymmetry relates to performance-a large-scale dichotic listening study. Front. Psychol. 4:997. doi: 10.3389/fpsyg.2013.00997

Hirnstein, M., Hugdahl, K., and Hausmann, M. (2014b). Erratum: how brain asymmetry relates to performance-a large-scale dichotic listening study. Front. Psychol. 5:58. doi: 10.3389/fpsyg.2014.00058

Hopkins, W. D., Misiura, M., Reamer, L. A., Schaeffer, J. A., Mareno, M. C., and Schapiro, S. J. (2014). Poor receptive joint attention skills are associated with atypical gray matter asymmetry in the posterior superior temporal gyrus of chimpanzees (Pan troglodytes). Front. Psychol. 5:7. doi: 10.3389/fpsyg.2014.00007

Iani, C., Milanese, N., and Rubichi, S. (2014). The influence of prior practice and handedness on the orthogonal Simon effect. Front. Psychol. 5:39. doi: 10.3389/fpsyg.2014.00039

Izura, C., Wright, V. C., and Fouquet, N. (2014). Hemispheric asymmetries in word recognition as revealed by the orthographic uniqueness point effect. Front. Psychol. 5:244. doi: 10.3389/fpsyg.2014.00244

Kéïta, L., Bedoin, N., Burack, J. A., and Lepore, F. (2014). Switching between global and local levels: the level repetition effect and its hemispheric asymmetry. Front. Psychol. 5:252. doi: 10.3389/fpsyg.2014.00252

Knudsen, E. I. (2007). Fundamental components of attention. Annu. Rev. Neurosci. 30, 57-78. doi: 10.1146/annurev.neuro.30.051606.094256

Manns, M., and Ströckens, F. (2014). Functional and structural comparison of visual lateralization in birds-similar but still different. Front. Psychol. 5:206. doi: 10.3389/fpsyg.2014.00206

Marsh, J. E., Pilgrim, L. K., and Sörqvist, P. (2013). Hemispheric specialization in selective attention and short-term memory: a fine-coarse model of left- and right-ear disadvantages. Front. Psychol. 4:976. doi: 10.3389/fpsyg.2013.00976

Marzoli, D., Prete, G., and Tommasi, L. (2014). Perceptual asymmetries and handedness: a neglected link? Front. Psychol. 5:163. doi: 10.3389/fpsyg.2014.00163

Meyer, G., Spray, A., Fairlie, J., and Uomini, N. (2014). Inferring common cognitive mechanisms from brain blood-flow lateralisation data obtained with functional transcranial Doppler ultrasound. Front. Psychol. 5:552. doi: 10.3389/fpsyg.2014.00552

Morton, B. E. (2013). Behavioral laterality of the brain: support for the binary construct of hemisity. Front. Psychol. 4:683. doi: 10.3389/fpsyg.2013.00683

Ocklenburg, S., Güntürkün, O., and Beste, C. (2011). Lateralized neural mechanisms underlying the modulation of response inhibition processes. Neuroimage 55, 1771-1778. doi: 10.1016/j.neuroimage.2011.01.035

Ocklenburg, S., Güntürkün, O., and Beste, C. (2012). Hemispheric asymmetries and cognitive flexibility: an ERP and sLORETA study. Brain Cogn. 78, 148-155. doi: 10.1016/j.bandc.2011.11.001

Ocklenburg, S., Ness, V., Güntürkün, O., Suchan, B., and Beste, C. (2013a). Response inhibition is modulated by functional cerebral asymmetries for facial expression perception. Front. Psychol. 4:879. doi: 10.3389/fpsyg.2013.00879

Ocklenburg, S., Ströckens, F., and Güntürkün, O. (2013b). Lateralisation of conspecific vocalisation in non-human vertebrates. Laterality 18, 1-31. doi: 10.1080/1357650X.2011.626561

Önal-Hartmann, C., Pauli, P., Ocklenburg, S., and Güntürkün, O. (2012). The motor side of emotions: investigating the relationship between hemispheres, motor reactions and emotional stimuli. Psychol. Res. 76, 311-316. doi: 10.1007/s00426-011-0337-4

Ooki, S. (2014). An overview of human handedness in twins. Front. Psychol. 5:10. doi: 10.3389/fpsyg.2014.00010

Oppenheimer, J. M. (1977). Studies of brain asymmetry: historical perspective. Ann. N.Y. Acad. Sci. 299, 4-17. doi: 10.1111/j.1749-6632.1977.tb41892.x

Pellicano, A., Barna, V., Nicoletti, R., Rubichi, S., and Marzi, C. A. (2013). Interhemispheric vs. stimulus-response spatial compatibility effects in bimanual reaction times to lateralized visual stimuli. Front. Psychol. 4:362. doi: 10.3389/fpsyg.2013.00362 
Prichard, E., Propper, R. E., and Christman, S. D. (2013). Degree of handedness, but not direction, is a systematic predictor of cognitive performance. Front. Psychol. 4:9. doi: 10.3389/fpsyg.2013.00009

Propper, R. E., and Brunyé, T. T. (2013). Lateralized difference in tympanic membrane temperature: emotion and hemispheric activity. Front. Psychol. 4:104. doi: 10.3389/fpsyg.2013.00104

Rugani, R., Rosa Salva, O., and Regolin, L. (2014). Lateralized mechanisms for encoding of object. Behavioral evidence from an animal model: the domestic chick (Gallus gallus). Front. Psychol. 5:150. doi: 10.3389/fpsyg.2014.00150

Scharoun, S. M., and Bryden, P. J. (2014). Hand preference, performance abilities, and hand selection in children. Front. Psychol. 5:82. doi: 10.3389/fpsyg.2014.00082

Specht, K., Baumgartner, F. J., Stadler, J., Hugdahl, K., and Pollmann, S. (2014). Functional asymmetry and effective connectivity of the auditory system during speech perception is modulated by the place of articulation of the consonant- A 7T fMRI study. Front. Psychol. 5:549. doi: 10.3389/fpsyg.2014.00549

Stock, A. K., and Beste, C. (2014). Lateralization of spatial information processing in response monitoring. Front. Psychol. 5:22. doi: 10.3389/fpsyg.2014.00022

Ströckens, F., Güntürkün, O., and Ocklenburg, S. (2013). Limb preferences in non-human vertebrates. Laterality 18, 536-575. doi: 10.1080/1357650X.2012. 723008
Thoma, P., Soria Bauser, D., Norra, C., Brüne, M., Juckel, G., and Suchan, B. (2014). Do you see what I feel?-Electrophysiological correlates of emotional face and body perception in schizophrenia. Clin. Neurophysiol. 125, 1152-1163. doi: 10.1016/j.clinph.2013.10.046

Conflict of Interest Statement: The authors declare that the research was conducted in the absence of any commercial or financial relationships that could be construed as a potential conflict of interest.

Received: 17 September 2014; accepted: 19 September 2014; published online: 08 October 2014.

Citation: Ocklenburg S, Hirnstein M, Beste C and Güntürkün O (2014) Lateralization and cognitive systems. Front. Psychol. 5:1143. doi: 10.3389/fpsyg.2014.01143

This article was submitted to Cognition, a section of the journal Frontiers in Psychology.

Copyright (C) 2014 Ocklenburg, Hirnstein, Beste and Güntürkün. This is an openaccess article distributed under the terms of the Creative Commons Attribution License (CC BY). The use, distribution or reproduction in other forums is permitted, provided the original author(s) or licensor are credited and that the original publication in this journal is cited, in accordance with accepted academic practice. No use, distribution or reproduction is permitted which does not comply with these terms. 